\title{
A AVALIAÇÃo DO ALUNO SURDO EM CLASSE INCLUSIVA NA REDE PÚBLICA DE ENSINO DO DISTRITO FEDERAL
}

FRANCISCA BONFIM DE MATOS RODRIGUES

\author{
Mestra em Educação, graduada em Letras e Pedagogia pela Universidade de Brasília. Professora formadora da \\ Secretaria de Estado de Educação do Distrito Federal, atuando na docência e orientação de trabalhos no curso de $1^{\mathrm{a}}$ \\ licenciatura em Pedagogia/PARFOR. \\ E-mail: francisca_mestrado@yahoo.com.br
}

LARISSA PEREIRA GONÇALVES

Especialista em Ensino de Português como segunda Língua para estudantes surdos e/ou com deficiência aditiva pelo Instituto de Letras, Departamento de Linguística da Universidade de Brasília. Graduada do curso de $1^{\mathrm{a}}$ Licenciatura em Pedagogia/PARFOR, intérprete de Libras. Professora da Educação Básica da Secretaria de Estado de Educação do

Distrito Federal. Bacharel em Fonoaudiologia pelo Centro Universitário Planalto do Distrito Federal. E-mail: larissafono@gmail.com

\section{RESUMO}

O artigo tem como objetivo caracterizar a avaliação do aluno surdo em fase de escolarização, matriculado em classe inclusiva no Ensino Fundamental. Para compreender a avaliação do aluno surdo dentro do contexto de inclusão, o estudo buscou realizar um breve histórico das abordagens pedagógicas realizadas nessa especificidade, bem como aspectos relevantes sobre as teorias da linguagem que se constituem como recurso importante para a participação e o exercício da cidadania. Diante da complexidade que permeia o ato educativo, a avaliação representa um processo contínuo e sistemático com vistas à melhor organização do trabalho pedagógico voltado para a especificidade do aluno surdo, especialmente, por revelar novos níveis de aprendizagem e desenvolvimento desse estudante. $\mathrm{O}$ caminho metodológico baseou-se na pesquisa qualitativa e o método utilizado foi o estudo de caso. Participaram desse estudo onze profissionais de uma escola pública da Secretaria de Estado de Educação do DF, um coordenador pedagógico, quatro professores intérpretes e seis regentes. Foram analisadas questões referentes à organização do trabalho pedagógico dos profissionais, aos critérios e parâmetros utilizados por eles na avaliação dos alunos surdos. Foram utilizados os seguintes instrumentos: análise documental, observação e entrevista semiestruturada. Como resultado essencial, foi constatado que a avaliação do aluno surdo diferencia-se a depender do perfil da turma em que está inserido. Nas classes ditas bilíngues, não há interação entre os professores intérpretes e regentes, ficando a avaliação sob total responsabilidade do professor intérprete. As crianças surdas não são priorizadas no planejamento diário dos professores regentes, que delegam esse compromisso ao professor intérprete. As turmas, nas quais não há presença do intérprete, o professor regente, com formação em LIBRAS, realiza o atendimento do aluno surdo e o integra à organização pedagógica do cotidiano de sala de aula. Foi evidenciada uma baixa expectativa dos docentes sobre as potencialidades dos alunos surdos, refletindo na qualidade do ensino oferecido e no processo de avaliação.

Palavras-chave: Surdez. Inclusão do aluno surdo. Avaliação escolar

\section{THE DEAF STUDENT ASSESSMENT IN INCLUSIVE CLASS IN THE FEDERAL DISTRICT'S PUBLIC SCHOOL}

\begin{abstract}
The purpose of this article is characterize the deaf student assessment in elementary school inclusive classes. To understand the deaf student assessment in an inclusion process, this study bring forward a brief history of the pedagogical approaches specific of deaf education, including relevant aspects of language theories, very important to the exercise of citizenship. On the complexity of educational situations, the assessment has a key role in the organization of the pedagogical work, because it revels the learning levels of this student group. The methodological
\end{abstract}


work has based on qualitative research, a case study. Eleven professionals from a public school participated of this study. One educational counselor, four interpreter teachers and six teachers. The organization of the pedagogical work and the assessment parameters applied for the deaf students was analyzed using semi-structured interview, observations and documentary analysis. The finding results evidence a different deaf student assessment, according to the class where he is included. In the bilingually classes, the two teacher (the principal teacher and the interpreter teacher) don't work together, as recommended. The evaluations of this students are made exclusively by the interpreter teacher. The necessities of deaf children has no priority on the class daily planning. This responsibility is delegated to the interpreter teacher. Was observed a low expectation on the academic future of the deaf students, affecting the quality of the education offered to this group of students.

Key-words: Deafness. Inclusion of Deaf. School Assessment.

\section{Introdução}

A educação de surdos, ao longo das décadas, vem sendo conduzida por correntes filosóficas e educacionais a partir de diferentes perspectivas teóricas. Cada uma destas encontrou o seu espaço nos contextos históricos nas quais foram desenvolvidas.

No Brasil, a educação de surdos teve início no ano de 1857, com a criação do Instituto Imperial dos Surdos-Mudos, atual Instituto Nacional de Educação de Surdos. Naquela época, ainda eram muito incipientes os pressupostos da educação de surdos, as próprias famílias apresentavam resistência em educa-los. A segunda escola para atender a esses estudantes só foi aberta na década de 20. Desde a criação desta escola até a década de 60, o ensino voltado para os surdos esteve ancorado na filosofia oralista, que entre as décadas de 70 e 80 passou a ser criticada. A partir da década de 80, surgiu uma nova proposta para educação de surdos que se caracterizou como o bilinguismo. (BUENO, 1994).

A educação de surdos brasileira e sua história fazem parte de uma trajetória de inclusão e exclusão do indivíduo surdo em todo o mundo. Há séculos, muitas culturas ocidentais condenavam os surdos à morte ou a uma vida de desprezos, descréditos e condenação à loucura (BRASÍLIA, 2004).

A primeira escola pública registrada para surdos foi fundada na França em 1755 e lá se desenvolveu uma estratégia de ensino de fala para os alunos, o oralismo (BRASÍLIA, 2004). Historicamente, foi observada a presença do oralismo - método de ensino para surdos que privilegia o aprendizado da fala, ou oralização - em diversos lugares do mundo nos quais foi implantada a educação de surdos. Aspecto que levou à reflexão sobre a existência de fortes indícios embasados na necessidade de "igualizar" a educação do surdo à pessoa ouvinte.

Tal reflexão possibilitou encaminhar algumas mudanças no processo educativo, relacionadas à inclusão do aluno surdo que, desde então, foram ocorrendo. Entretanto o potencial acadêmico do 
aluno surdo não foi adequadamente desenvolvido, em virtude de uma prática constante de “ouvintização", por meio da qual esses estudantes eram submetidos à imposição do oralismo tanto por profissionais da saúde quanto por professores que acreditavam ter o surdo, a obrigação de adequar-se à sociedade ouvinte (STROBEL, 2006, p. 246).

A Lei 10.436/ 2002 representou uma conquista diante da luta constante das comunidades surdas pelo reconhecimento da Língua Brasileira de Sinais (LIBRAS), como a língua do surdo brasileiro. Se constituiu como um importante marco para a compreensão social sobre a comunicação e expressão do indivíduo surdo a partir da língua de sinais. Outra legislação foi elaborada, referendando o teor daquela Lei, a saber: o Decreto $\mathrm{n}^{\circ} 5.626$ de 22 de dezembro de 2005.

Tais legislações unidas à declaração de Salamanca e aos estudos realizados ao longo dos anos sobre o desenvolvimento da criança surda e a importância da escolarização neste processo, os modelos de educação inclusiva, bem como as filosofias que as norteavam foram avançando do oralismo puro, para a comunicação total até chegar ao sistema de educação bilíngue, adotado hoje nas escolas da rede pública de ensino do Distrito Federal.

Ainda que o amparo legal se constitua como uma nova compreensão do atendimento ao aluno surdo, na sua singularidade e necessidades de adequações pedagógicas, dentro do contexto escolar, muitos entraves no cotidiano findam por revelar uma fragilidade na organização do trabalho pedagógico voltado para esse público. Os próprios exames nacionais apresentam baixos índices de desempenho acadêmico dos estudantes em início de escolarização. Mesmo que não mencionem quantitativos de crianças com necessidades especiais, elas estão presentes na escola e participam das avaliações em larga escala.

O interesse em caracterizar as estratégias avaliativas para com o aluno surdo, bem como as expectativas dos professores sobre o seu desenvolvimento acadêmico, representaram uma importante motivação para esse estudo. Para uma apresentação mais didática da pesquisa, optou-se por definir a surdez, posteriormente, discorrer sobre inclusão do aluno surdo na escola Pública da SEEDF, o papel dos professores envolvidos no processo de ensino e aprendizagem bem como a importância da avaliação processual como princípio norteador do trabalho pedagógico e sua importância para o desenvolvimento e aprendizagem do aluno surdo.

\section{Da surdez e da proposta da SEEDF para inclusão do aluno surdo}

A perda auditiva ou disacusia (HUNGRIA, 2000, p. 427) é uma patologia com diversas características que acomete indivíduos tanto de forma congênita quanto adquirida ao longo da vida. Para este artigo, considera-se o conceito de surdez estabelecido no cap. I, §único, do Decreto 
5.626/05, que considera a deficiência auditiva como "[...] a perda bilateral, parcial ou total, de quarenta e um decibéis $(\mathrm{dB})$ ou mais, aferida por audiograma nas frequências de $500 \mathrm{~Hz}, 1.000 \mathrm{~Hz}$, $2.000 \mathrm{~Hz}$ e $3.000 \mathrm{~Hz}$ " (BRASIL, 2005).

As disacusias neurossensoriais podem apresentar diferentes graus de classificação - de leve a profunda - bilaterais ou unilaterais. De acordo com Hungria (2000), esse tipo de surdez caracteriza-se por lesões presentes na orelha interna, que podem ser no nervo ou nas células ciliadas - responsáveis por parte da percepção auditiva - provocadas por etiologias diversas.

Quadros (2003) afirma que existem dois parâmetros básicos de visão da surdez, por um lado considerada como deficiência, por outro, considerada como diferença, cuja autora as caracteriza como "a concepção clínica de surdez e a sócio antropológica” (QUADROS, 2003, p. 88). A diferença principal entre elas está na concepção da surdez como deficiência, visto que tributa ao indivíduo surdo um rótulo de que algo nele precisa ser normatizado, padronizado. Ao analisar a surdez como diferença e, a partir da perspectiva sócio antropológica, compreende-se a surdez como uma outra forma de enxergar o mundo e construir conceitos.

De acordo com Goldfeld (2003), a pessoa surda, especialmente, a que nasce surda ou desenvolve a surdez no período linguístico (até por volta de 3 anos de idade), apresenta como característica a presença de algumas dificuldades no processo de aquisição da linguagem que surgem durante seu desenvolvimento. Diante disso, o surdo precisa ser devidamente estimulado, aspecto que retifica a importância do papel escolar neste processo. Assim, no caso da criança surda "quanto mais cedo tenha sido privado de audição e quanto mais profundo for o comprometimento maiores serão as dificuldades educacionais, caso não receba atendimento adequado" (BRASÍLIA, 2003, p. 18).

Quando o indivíduo não é exposto ou não tem contato adequado com sua primeira língua no período dito linguístico - período natural da aquisição de uma língua - ele sofre importantes e irremediáveis danos no que diz respeito à sua organização psicossocial (QUADROS, 1997). A criança surda, filha de pais ouvintes, tende a não desenvolver total proficiência em Libras (doravante L1) por não receber os inputs $^{1}$ adequados durante o período linguístico, correndo riscos de ficar atrasada no que se refere à compreensão e à expressão em sua própria língua (LIMA, 2011).

Um fato de extrema importância a ser considerado é que o indivíduo, seja ele surdo ou ouvinte, constrói a sua subjetividade e a sua visão de mundo por meio de sua primeira língua. Essa compreensão de contextos se dá à medida que existe interação entre pares usuários de uma mesma

\footnotetext{
${ }^{1}$ Input: termo emprestado à linguagem da Informática e adotado no âmbito da aquisição de línguas para designar o conjunto de enunciados de uma língua que o aprendiz ouve e/ou lê.
} 
língua. É por meio da comunicação que se tem acesso à cultura e às relações sociais do meio no qual a pessoa está inserida.

Para Lodi (2004) as relações dialógicas com os outros são responsáveis pela constituição do indivíduo como sujeito por meio de um processo cercado de dinamismo. É nessa experiência que as pessoas constroem laços e se definem como participantes de um grupo no qual percebem a si mesmos e aos outros, compartilhando a sua existência.

Crianças surdas, filhas de pais ouvintes, muitas vezes crescem isoladas dentro do próprio ambiente familiar e na busca por uma comunicação mínima, criam um sistema de "sinais caseiros", que não constituem língua de sinais e nem a língua portuguesa. O surdo está inserido em uma cultura de língua oral sem ter condições de apropriar-se dela, impedindo assim uma adequada interpretação dos contextos sociais (DALCIN, 2006).

Dessa maneira, o surdo vive um período importantíssimo para a aquisição da linguagem em uma lacuna, um vazio de conhecimentos dos mais diversos, afetando diretamente o seu conhecimento de mundo.

"Isolados no meio familiar, impossibilitados de se apropriar da língua materna - a língua oral - eles não têm condições de compartilhar o mesmo código que a mãe. Em consequência, ficam expostos a graves restrições linguístico-sócio-culturais que acarretam sérias limitações quanto a sua subjetividade” (DALCIN, 2006, p. 192, 193).

Essa inconsistência na aquisição de conceitos básicos por privação da comunicação em primeira língua acaba levando o indivíduo surdo a uma situação, cuja construção de seu pensamento ocorre de forma desorganizada, imatura e sem alicerces ou recursos para que ele faça as associações necessárias com bases conceituais que o leve a compreender o que acontece ao seu redor (op. cit.).

Levando em consideração que apenas $5 \%$ das crianças surdas são filhas de pais surdos falantes nativos de LIBRAS/ língua brasileira de sinais - e os demais 95\% filhos de ouvintes, o processo de aquisição da língua natural da grande maioria dessas crianças acontece no ambiente escolar que, por essa razão, acaba assumindo um papel imprescindível por ser o primeiro espaço de contato do surdo com sua primeira língua (QUADROS, 2006).

Para entender o processo de inclusão do indivíduo surdo, é necessário realizar um breve histórico das abordagens pedagógicas realizadas na educação de surdos no Brasil nas últimas décadas, bem como apresentar apontamentos sobre as teorias de linguagem, dada a impossibilidade de abordar a educação de surdos e todas as suas vertentes, sem apresentar tais compreensões. Dessa constatação, pode-se traçar um horizonte sobre a avaliação do surdo dentro do contexto de escola inclusiva observado durante este estudo. 
De acordo com Fernandes (2003, p. 1), o conceito de linguagem é amplo e não se refere somente à comunicação por meio de uma ou mais línguas específicas, mas podem ser desenvolvidos sistemas que comunicam uma mensagem de forma humana ou não. A autora cita a linguagem corporal para exemplificar essa definição, e outros sistemas de comunicação, tais como: as expressões faciais, placas de aviso, cores com significado comunicativo. Todas estas situações de comunicação são permeadas pela linguagem.

Lyons (1987, p. 187) defende que "não se pode possuir (ou usar) a linguagem sem possuir (ou usar) alguma língua determinada”. Conhecer uma língua humana - sistema com alta complexidade - e apropriar-se dela é um "feito intelectual extraordinário para uma criatura não especificamente dotada para realizar tal tarefa" (CHOMSKY, 1980, p.10).

As línguas fazem parte da linguagem. Existem línguas orais auditivas ou espaço visuais. As línguas orais são as faladas e utilizadas por quase toda a sociedade enquanto as línguas espaço visuais são usadas por grupos específicos de falantes, como é o caso das línguas de sinais espalhadas pelo mundo. Essas línguas são adquiridas e desenvolvidas pelos seres humanos de maneiras diversas (FERNANDES, 2003, p. 4).

O uso da linguagem é essencial para a participação de qualquer pessoa na sociedade. É por meio dela que se expressam sentimentos, pensamentos e ideias que lhe são inerentes, bem como se constrói uma capacidade superior de cognição (BRASÍLIA, 2003, p. 15). Fernandes (2003, p. 6 e 7) afirma que o indivíduo precisa estar em contato com falantes da língua para receber os estímulos necessários para a aquisição e desenvolvimento da linguagem.

Os surdos desenvolvem a sua língua por meio do sistema motor de comunicação, por isso as línguas de sinais são ditas como suas línguas naturais, enquanto a língua hegemônica praticada na sociedade na qual estão inseridos - no nosso caso o Português - trata-se de uma língua de segunda aquisição, denominada oficialmente de L2, tanto em sua modalidade escrita como em sua modalidade oral (BRASÍLIA, 2003). Essa é a concepção mais importante que permeia o modelo de inclusão adotado no Distrito Federal na atualidade.

A LIBRAS (doravante L1) é a língua natural ou primeira língua do surdo brasileiro. Estudos mostram que crianças surdas e ouvintes adquirem sua L1 em condições análogas ou idênticas. Contudo, para que a aquisição da língua de sinais ocorra é de extrema necessidade que a criança seja a ela exposta por meio da convivência com falantes nativos dessa (SALLES e NAVES, 2010).

A primeira visão que se tinha sobre a surdez, conforme citada anteriormente, tinha como foco a caracterização do surdo como "normal". Era uma tentativa de homogeneizar os indivíduos, característica de uma educação em um modelo mais positivista. Sob essa perspectiva, estava o oralismo, uma filosofia educacional na qual o surdo deveria apropriar-se da língua oral de seu país. 
Esta foi uma visão que ocupou as escolas durante décadas (GOLDFELD, 2002, p. 34), acrescenta o autor que:

\footnotetext{
"São considerados oralistas os profissionais e instituições que seguem o ideal de ensinar a língua oral ao deficiente auditivo, negando e considerando prejudicial para o seu desenvolvimento o contato com a Língua de Sinais ou qualquer outro código na modalidade espaço-visual" (GOLDFELD, 2003, p. 99).
}

Oliver Sacks (2010) relata que antes de 1750, os surdos profundos pré-linguísticos, ou seja, aqueles que ou nasceram surdos ou perderam a surdez antes de aprenderem a falar, eram tratados como incapazes. Eles sofriam vários tipos de privações, a saber: não tinham acesso a nenhum tipo de instrução, eram forçados a realizar os piores trabalhos, eram tratados como "estorvos" dentro de seus círculos familiares e como pessoas amaldiçoadas.

Mais ao final da idade média, quando alguns médicos e clérigos começam a observar o desenvolvimento do surdo é que se chegou à conclusão de que ele era capaz de aprender, podendo assim adaptar-se aos padrões sociais. No século XVI o médico italiano Gerolamo Cardano concluiu que o surdo possuía a habilidade de raciocinar e que poderia ser ensinado a escrever, para poder comunicar-se com os demais (MESERLIAN e VITALIANO, 2009).

A esse respeito afirmam Silva et. al (2015) que:

\begin{abstract}
Apenas com o Iluminismo, intelectuais e pesquisadores começam a se interessar cientificamente pela surdez, época em que surgem as primeiras experiências na educação de surdos, a partir do século XVI. As iniciativas educacionais são ainda pontuais, seja pela educação oferecida pela nobreza aos seus filhos surdos com a orientação de preceptores que ensinavam a ler e a escrever, seja pela via das entidades religiosas com caráter filantrópico que se dispunham a ensinar surdos que viviam em situação de mendicância" (SILVA et. $a l, 2015$, p.3) .
\end{abstract}

O Congresso Internacional de Surdo-Mudez, ocorrido em 1880, em Milão, foi um importante evento e representou um marco histórico com um imenso impacto na vida dos surdos no mundo inteiro e teve grande influência de Alexander Graham Bell. A partir desse evento, foi estabelecido que, nas escolas e institutos de educação de surdos, a metodologia a ser adotada para a instrução seria a oral. Após uma acalorada discussão, chegou-se à conclusão - não unanime, vale ressaltar - de que o uso das línguas gestuais deixaria os surdos "preguiçosos" para aprender a falar (MESERLIAN e VITALIANO, 2009).

Durante longos anos, o surdo permaneceu "proibido" de fazer uso da língua de sinais, pois acreditava-se que isto lhes impediria o desenvolvimento de sua oralidade. Entretanto, os resultados alcançados pelo surdo por meio do oralismo ficaram aquém dos níveis satisfatórios. Ao contrário, os surdos passavam anos no sistema de ensino e saíam sem o mínimo de conhecimento, se comparados aos ouvintes (SILVA et. al, 2015). 
Esta linha pedagógica passou a sofrer várias críticas no meio da comunidade surda. Além disso, o linguista William Stockoe publicou um artigo no qual ele comprovava que a Língua de Sinais era efetivamente uma língua. A partir daquele momento, o surdo passou a ser visto como "diferente" e não mais deficiente, surgiu, portanto a corrente filosófica educacional da Comunicação Total. (GOLDFELD, 2003, p. 100).

Souza contribui com a apresentação do conceito de Comunicação Total como uma abordagem que,

"privilegia a comunicação e a interação e não apenas a língua. A filosofia da Comunicação Total defende o uso de qualquer recurso linguístico, seja a língua de sinais, a língua oral e códigos manuais para facilitar a comunicação com as pessoas surdas" (SOUZA, 2011, p. 74).

A autora defende ainda que a Comunicação Total surgiu dada a imensa necessidade encontrada pelos professores de uma metodologia que realmente atingisse o indivíduo surdo e ainda assim, ela não tinha como foco o ensino das línguas de sinais. Para a autora, o principal passo dado pela Comunicação Total foi o de retirar a língua de sinais do campo da proibição para que esta começasse assim a ganhar espaços nas discussões científicas.

A terceira abordagem filosófica da educação de surdos é inclusive a mais aceita pela comunidade surda e pelos profissionais que hoje atuam nessa área da educação inclusiva: o bilinguismo. Lacerda (2006, p. 165) esclarece que a proposta de educação bilíngue contempla a LIBRAS como a primeira língua do surdo e é a partir dela que ele entrará em contato com a língua hegemônica da sociedade na qual está inserido.

O caderno "Saberes e Práticas da Inclusão" do MEC (BRASÍLIA, 2006) esclarece que:

"A educação bilíngue para crianças brasileiras com surdez consiste na aquisição de duas
línguas: a língua brasileira de sinais (LIBRAS) e a língua portuguesa (modalidades oral e
escrita), com professores diferentes em momentos diferentes, a depender da escolha
pedagógica da escola e da família" ((BRASÍLIA, 2006, p. 22).

Ainda sobre a educação bilíngue, Tuxi (2009) afirma que:

"A proposta bilíngue busca resgatar o direito da pessoa surda de ser ensinada em sua língua, levando em conta os aspectos sociais e culturais em que está inserida. [...] as classes de educação bilíngue são aquelas em que a LIBRAS e a modalidade escrita da língua portuguesa são línguas de instrução utilizadas no desenvolvimento de todo o processo educativo" (TUXI ,2009, p.22). 
Lacerda (2006, p. 181) afirma que, para o aprendiz surdo, especialmente no ensino fundamental, há necessidade de que os conteúdos sejam ministrados em sua língua, ou seja, o ideal seria que a língua de instrução desses alunos fosse a Língua Brasileira de Sinais e os profissionais e outros alunos da escola também fizessem uso da língua de sinais como meio principal de comunicação entre os alunos surdos e ouvintes.

Machado (2006) destaca ser necessário incluir o aprendiz surdo nos sistemas regulares de ensino e que sejam respeitadas as suas características linguísticas. $\mathrm{O}$ autor alerta que, caso isso não ocorra, os estudantes surdos sofrerão prejuízos em todo o seu processo de ensino aprendizagem, uma vez que os contextos comunicativos nos quais são inseridos alunos com outras necessidades especiais ou outras privações sensoriais, não lhes atendem quanto às necessidades básicas de ensino que a surdez requer.

O movimento de educação inclusiva ganhou força e visão após a Declaração de Salamanca em 1994, que trouxe em seu corpo documental a responsabilidade das instituições de ensino de permitir que os alunos, independente, de sua origem étnica, racial, social e linguística ocupassem o mesmo espaço escolar, pois cada criança é importante para a construção de um processo educacional baseado no respeito à diversidade (LACERDA, 2006, p. 167).

Na prática, o modelo de inclusão na atualidade acaba por promover também a exclusão e a segregação dentro do próprio ambiente "inclusivo". De acordo com Razuck (2011, p. 47) "os alunos frequentam um espaço físico escolar, mas não se sentem pertencentes a estes, pois seus colegas e professores parecem não acreditar em seu potencial de desenvolvimento".

Essa questão se justifica, pois se observa que estes estudantes são acompanhados e avaliados pelo professor intérprete e pelos professores da sala de recursos ${ }^{2}$, enquanto os professores regentes permanecem alheios ao seu processo de desenvolvimento e aprendizagem, como se os surdos fossem "estrangeiros" dentro do ambiente da sala de aula.

Faz-se importante destacar que a avaliação faz parte de todo o trabalho pedagógico do cotidiano escolar. A ação de discutir e refletir avaliação docente implica também em refletir que avaliar faz parte do processo de ensino e de aprendizagem: não ensinamos nem aprendemos sem avaliar. Dessa forma, dialogar a respeito da avaliação pode promover reflexões que apontem para uma ruptura com a falsa dicotomia entre ensino e avaliação, como se esta fosse apenas o final de um processo (BRASÍLIA $1 *$, 2014).

Sob essa perspectiva, é importante pensar sobre o processo de avaliação, que pode acontecer em parceria entre os docentes que atuam no contexto de inclusão, implicando em

\footnotetext{
${ }^{2}$ As salas de recursos oferecem atendimento especializado em que apoia e complementa o atendimento educacional realizado nas classes comuns.
} 
benefícios para o aluno. Sabendo ser a escola um lugar de construção da autonomia e da cidadania, cuja avaliação dos processos, sejam eles das aprendizagens, da dinâmica escolar ou da própria instituição, não deve ficar sob a responsabilidade apenas de um ou de outro profissional, é uma responsabilidade tanto da coletividade, como de cada um em particular.

\section{O campo de pesquisa e o percurso teórico-metodológico}

Para o levantamento das informações, a partir de uma abordagem metodológica de natureza qualitativa, conforme Ludke e André (1986), foram realizadas entrevistas semiestruturadas, observações junto aos professores intérpretes e regentes bem como à coordenação pedagógica da escola.

Tais instrumentos objetivaram construir informações sobre a percepção da expectativa dos professores com relação ao desenvolvimento e aprendizagem dos alunos, verificar o perfil e formação do professor atuante na educação de surdos na escola, evidenciar a dinâmica de trabalho destes profissionais e caracterizar o processo de avaliações dos alunos. Nesse ponto, questionou-se sobre a visão do professor a respeito da ação de avaliar e dos parâmetros e critérios utilizados nesse processo para chegar a conclusões sobre o desenvolvimento e aprendizagem dos alunos inclusos.

Foi realizado um estudo de caso em uma escola, cuja proposta de inclusão e integração do surdo estava ancorada na abordagem metodológica sob perspectiva de educação bilíngue. Segundo Razuck (2011), a Secretaria de Educação traz em seus documentos a proposta de um professor de LIBRAS para os alunos surdos, com o objetivo de promover aos estudantes, [...] contato e consequente domínio da língua (RAZUCK p. 47).

Sobre os alunos, da escola selecionada para este estudo, apresentavam disacusias neurossensoriais em diferentes gruas de classificação. As políticas propostas pelo governo federal determinam que os alunos com necessidades educacionais especiais sejam inclusos nos ambientes escolares indiscriminadamente.

Sob este direcionamento, os alunos surdos são matriculados nas escolas públicas do DF de acordo com a portaria 244/ 2014 que define a Estratégia de Matrícula. Seguindo esse documento, as turmas da escola pesquisada estavam organizadas em Classe Comum Inclusiva (bilíngue), constituída por estudantes do ensino regular e surdos, e em Classes Bilíngues Mediadas, formadas por alunos das classes comuns e alunos surdos, com a presença do professor, formado em LIBRAS, atuando como intérprete em parceria com o professor regente

Classe Comum Inclusiva (bilíngue), havia obrigatoriedade do professor ter conhecimento das características linguísticas do estudante surdo, mas não havia obrigatoriedade da instrução 
ocorrer, durante todo o período de aula, na língua de sinais. Nas classes Bilíngues Mediadas não é exigida a formação docente em LIBRAS (BRASÍLIA, 2014, p. 23-27).

Sobre os professores participantes, observou-se que possuíam faixas etárias heterogêneas e predominavam, em sua maioria, docentes do gênero feminino. Quanto ao perfil de formação, dos onze profissionais, nove tinham formação superior em Pedagogia, um tinha licenciatura plena em História, e outro docente tinha habilitação em Letras/ Português.

Quatro regentes não apresentaram formação ou cursos de LIBRAS, incluindo a coordenadora pedagógica. Os demais, realizaram cursos de LIBRAS oferecidos pela própria SEDF e por associações credenciadas, que ofereciam capacitação com mais de 300 horas em formação na língua de sinais, a saber: a Associação de Pais e Amigos do Deficiente Auditivo- APADA e a Federação Nacional de Estudo e Integração do Surdo-FENEIS.

\section{Análise e discussão dos resultados}

A utilização dos instrumentos foi flexível de forma que não houve impedimentos no processo de análise das informações em decorrência de rigidez em relação à ordem, ou formato de aplicação dos instrumentos. Vale ressaltar que a análise das informações caracterizou-se pela processualidade, a partir do acompanhamento de todos os momentos da pesquisa por meio da interpretação dos instrumentos, que foram obtidas em diferentes fontes.

A interpretação e construção das informações implicou detalhamento na análise dos instrumentos orais e escritos. As informações retiradas dos instrumentos escritos foram selecionadas a partir da leitura minuciosa de cada um deles. Em seguida, foram levantados indicadores que viabilizaram a elaboração de hipóteses que iam se confirmando ou não, à medida em que se confrontavam estes instrumentos

A utilização dos instrumentos partiu da seguinte ordem: conversa informal e análise documental; observação dos espaços de atuação docente. Em seguida, ocorreram as entrevistas semiestruturadas, que tiveram duração, cada uma, de aproximadamente uma hora e dez minutos,

A proposta principal de trabalho foi embasada na construção diálogos com os participantes da pesquisa. Partindo dessa rede relacional e interativa, buscou-se o fortalecimento de vínculos e espontaneidade entre as pesquisadoras e os participantes, a fim de que os elementos significativos e subjetivos também pudessem surgir na espontaneidade da relação e contribuíssem para compreender, em que medida estariam favorecendo positivamente o processo avaliativo do aluno surdo. 
As informações levantadas permitiram a constatação de que os aspectos pedagógicos referentes aos alunos surdos são planejados e organizados, exclusivamente, pelos professores intérpretes, especialmente, nas classes bilíngues mediadas. Os relatórios de desenvolvimento, documentos de adaptação curricular, adaptações de atividades e metodologias de ensino bem como o atendimento e a interação como os alunos, no cotidiano de sala de aula, são desenvolvidos somente pelo trabalho do professor intérprete, no caso das classes bilíngues mediadas, quando professor regente e professor intérprete atuam juntos.

Os professores regentes dessas turmas acreditam que os estudantes surdos não são seus alunos, mas estão sob a responsabilidade dos professores intérpretes. Esse é um erro comum no cotidiano das classes bilíngues mediadas. Contudo, é de extrema importância ressaltar que "a elaboração do Registro de Avaliação é de responsabilidade do docente que responde pela turma e ou por um determinado componente curricular" (BRASÍLIA, p. 48, 2014). A posição do intérprete e dos professores da sala de recursos, nesses casos, é o de profissionais capazes de colaborar na qualificação dos registros realizados pelo professor regente.

Quadros (2004) traz como definição que o intérprete educacional é o profissional que atua como intérprete de LIBRAS na educação. O seu papel, por definição é o de intermediar as relações entre alunos surdos e professores ouvintes não usuários de língua de sinais e entre o colega surdo e os demais colegas ouvintes. Contudo, a realidade das escolas acaba por fazer com que a função desse profissional se confunda com a função do professor.

$\mathrm{Na}$ dinâmica da sala de aula o que acaba acontecendo é que os alunos veem o intérprete como seu professor e dirigem a ele as questões, dúvidas e expectativas de ensino. Os professores regentes também delegam ao intérprete essa responsabilidade de ensinar aos alunos os conteúdos escolares. Quadros (2004) afirma:

\footnotetext{
"Muitas vezes, o papel do intérprete em sala de aula acaba sendo confundido com o papel do professor. Os alunos dirigem questões diretamente ao intérprete, comentam e travam discussões em relação aos tópicos abordados com o intérprete e não com o professor. 0 próprio professor delega ao intérprete a responsabilidade de assumir o ensino dos conteúdos desenvolvidos em aula ao intérprete. Muitas vezes, o professor consulta o intérprete a respeito do desenvolvimento do aluno surdo, como sendo ele a pessoa mais indicada a dar um parecer a respeito (QUADROS, 2004, p. 60)”.
}

Nas classes comuns inclusivas, sem a presença do intérprete (as turmas do Bloco Inicial de Avaliação), o professor regente já apresenta uma visão diferente e isso acaba por promover uma inclusão mais próxima da proposta pelos documentos, porém, em muitos momentos e atividades as necessidades dos alunos ouvintes - que consiste na maioria da turma - são priorizadas em detrimento das necessidades pedagógicas dos alunos surdos, começando pelas próprias questões linguísticas. 
As aulas não são ministradas na língua de instrução do aluno surdo, pois a LIBRAS não é a língua de instrução do aluno ouvinte. Os professores relataram ser esta a maior dificuldade na execução do trabalho pedagógico. Alguns sugeriram nos instrumentos como ideal que os alunos surdos, principalmente no primeiro e no segundo ano do ensino fundamental, deveriam ser atendidos em classes exclusivas para surdos, com professores preferencialmente fluentes em LIBRAS e com habilitação profissional para a docência no respectivo nível de ensino.

Prosseguindo com as análises das informações levantadas, a maioria dos professores relatou que os alunos surdos não estão no mesmo nível de desenvolvimento pedagógico dos alunos ouvintes, mesmo estando na mesma série. É importante levar em consideração que a maioria dessas crianças é considerada fora de faixa etária para o ano no qual estão matriculadas. A expectativa desses profissionais quanto ao prognóstico educacional dos estudantes, retrata uma triste realidade. A maioria deles, exceto dois professores acredita que, em nenhum momento da vida escolar dessas crianças, elas alcançarão o mesmo nível de desenvolvimento dos alunos ouvintes.

Essa crença finda por delinear o perfil profissional docente e o quanto ele está disposto a "realizar com sua turma de alunos, do quanto está disposto a desafiá-los" (RAZUCK, 2006, p. 50). A baixa expectativa sobre as potencialidades dos alunos influencia diretamente na qualidade do ensino oferecido por aquele professor, bem como na maneira como ele o vê durante o processo de avaliação.

As diretrizes de avaliação educacional (BRASÍLIA, 2014) trazem a seguinte observação sobre a avaliação informal:

"[...] seu uso formativo e, portanto, recomendável, ocorre quando identificamos as
fragilidades e as potencialidades desses atores e as utilizamos em favor deles, sem
compará-los com outros. [...] os elementos da avaliação informal demarcam fortemente a
relação diária dos docentes com os estudantes e, em consequência, influenciam os
processos de ensino e de aprendizagem que daí decorrem" (BRASÍLIA, 2014, p. 43).

Os professores, quando questionados sobre como se sentiam em relação às dificuldades dos alunos, foram unanimes em responder que, em muitos momentos, se viam impotentes. Alguns relataram que as metodologias utilizadas muitas vezes não contemplavam todas as necessidades dos estudantes, e, sem exceção, relataram que o modelo de inclusão adotado hoje pela SEEDF distancia-se do ideal. Sinalizaram a necessidade do desenvolvimento e execução de novas políticas públicas que permitam ao aluno surdo o acesso à educação de maneira igualitária ao ouvinte.

Sobre o processo de avaliação, os professores demonstraram bastante objetividade diante dos questionamentos: "não há critérios de avaliação definidos. Os critérios estão no próprio aluno, na maneira como ele começou o ano letivo e no seu processo de desenvolvimento, o que ele 
conseguiu alcançar e as barreiras que ainda encontra" (professor 07, entrevista semiestruturada, questão 01). Outro professor fez a seguinte observação: “como não sou eu quem avalio o aluno, mas o intérprete que está todo o tempo com ele em sala de aula, não faço ponderações, mas acredito que os critérios deveriam ser os mesmos adotados para a avaliação dos demais alunos, já que estão inclusos" (Professor 04, entrevista semiestruturada, questão 01).

Os profissionais entrevistados também relataram que a avaliação acontecia diariamente. Ela ocorria não apenas pelos “elementos formais que compõem a avaliação" (BRASÍLIA, p. 42, 2014), mas pela observação de tudo o que era realizado pelo aluno na sala de aula e também em momentos fora dela, onde ele interagia com os demais colegas e professores. Assim podemos inferir pelos relatos que a avaliação acontecia tanto por meio dos instrumentos formais como dos informais.

Os "elementos formais" que constituem o processo de avaliação são os mais comumente conhecidos, provas escritas ou orais, trabalhos e atividades realizados em casa, exercícios de sala de aula, atividades realizadas em grupo e outros. Em contrapartida, os "elementos informais", e tão importantes quanto os demais citados, são a visão que os professores têm sobre os alunos e a visão dos alunos sobre o professor. Os aspectos informais da avaliação são importantes porque por meio deles pode-se verificar e perceber aspectos do aluno que não são evidenciados na avaliação formal, mas que influenciam diretamente nos resultados da mesma. Isso inclui perceber questões sociais, culturais e emocionais dos alunos (BRASíLIA, p. 42 e 43, 2014).

Esse direcionamento é muito importante para reflexão sobre outro ponto abordado na pesquisa que se trata da maneira como são analisadas as avaliações formais dos alunos surdos. Considerando as diferenças linguísticas já citadas anteriormente, foi unanime a resposta dos professores ao dizer que esta característica do surdo precisa ser respeitada e aceita inclusive no processo de avaliação. Mas ao mesmo tempo, especialmente os professores regentes sem formação em LIBRAS, relataram não saber como fazer esta verificação de maneira adequada. Só essa distinção de olhar já estabelece uma diferença importante nos critérios de avaliação entre surdos e ouvintes.

\section{Considerações finais}

Para que a inclusão do surdo funcionasse, foram desenvolvidas e criadas diferentes propostas educacionais e estratégias de ensino. E como se observou neste estudo, no caso do aluno surdo a inclusão vai além de adaptações de espaços físicos ou de recursos didáticos metodológicos. Tuxi (2009) relata que é preciso reconhecer as necessidades linguísticas desses alunos para que o ensino e aprendizagem tenha significado, ao invés de meras reproduções de conteúdo. 
Assim sendo, não se pode falar em avaliação do surdo em processo de inclusão sem considerar a importância da formação do professor em LIBRAS - intérprete e regente - e seu conhecimento das características peculiares que envolvem o desenvolvimento da pessoa com surdez e seu processo de escolarização. Ficou claro na pesquisa que o fato de os professores regentes não apresentarem proficiência suficiente, especialmente no que diz respeito à língua, interfere diretamente na avaliação desses alunos bem como em todo o seu processo educativo.

Outra constatação importante é que se faz necessário rever os modelos de inclusão adotados hoje na secretaria de educação. A proposta de educação bilíngue conforme é recomendada por teóricos (QUADROS, SALLES et al., RAZUCK) é de difícil implantação com as atuais políticas de inclusão do aluno surdo, resumindo-a apenas à presença do intérprete educacional. Os resultados têm sido visivelmente insatisfatórios, diante das necessidades desses alunos em serem respeitados em suas peculiaridades linguísticas.

Além disso, para que a política de educação bilíngue atinja seus objetivos, é necessário promover uma formação de professores que efetivamente contemple as demandas que surgem em todo o processo de ensino e aprendizagem do aluno surdo. A baixa expectativa que se tem sobre os resultados que o surdo apresentará ao final de sua vida escolar, faz com as práticas pedagógicas adotadas não atendam às exigências para que o surdo alcance sucesso em sua jornada.

Se as definições sobre como se organizará o trabalho e a práxis pedagógica surgem durante o processo avaliativo, não é possível que a visão de que o surdo não seja tão capaz quanto o ouvinte de alcançar êxito acadêmico não interfira na qualidade de ensino oferecida a esses alunos. A eles devem ser ofertadas todos os recursos necessários para seu pleno desenvolvimento acadêmico, sócio afetivo e cultura.

O professor regente da turma não pode tornar-se dependente do professor intérprete para garantir que o surdo seja verdadeiramente incluso e tenha garantidos os seus direitos de uma educação de qualidade e uma avaliação processual que leve em conta toda a sua subjetividade. $\mathrm{O}$ ideal é que este trabalho seja feito em co-docência, ou seja, em uma parceria constante em todos os momentos da prática pedagógica. Enxergar o surdo com um sujeito único exige uma mudança de perspectivas para que o ambiente escolar se torne um local significativo para estes alunos.

\section{Referências}

BRASIL. (2005). Decreto 5.626/05. Regulamenta a Lei $n^{0} 10.436$, de 24 de abril de 2002, que dispõe sobre a Língua Brasileira de Sinais - Libras, e o art. 18 da Lei $\mathrm{n}^{\mathrm{o}} 10.098$, de 19 de dezembro de 2000. 
Disponível em: http://www.planalto.gov.br/ccivil_03/_ato2004-2006/2005/decreto/d5626.htm. Acesso em 02 jun. 2014

BRASÍllA. (2004). SALLES, Heloisa Maria Moreira Lima ... [et al.]. Ensino de Língua portuguesa para surdos: caminhos para a prática pedagógica. MEC, SEESP. Programa Nacional de Apoio à Educação de Surdos; v. 1.

. (2006). Educação Infantil Saberes e Práticas da Inclusão: Surdez. Secretaria de Educação Especial. Ministério da Educação. Brasília. 2006.

. (2014). Estratégia de Matrícula Rede Pública de Ensino do Distrito Federal 2015. Portaria no 244, de 19 de novembro de 2014. Secretaria de Educação do Distrito Federal. Brasília. 2014.

1*. (2014). Diretrizes de avaliação educacional: aprendizagem, institucional e em larga escala. 2014-106. Secretaria de Educação do Distrito Federal. Brasília. 2014.

BUENO, José Geraldo Silveira. A Educação do Deficiente Auditivo no Brasil: Situação Atual e Perspectivas. In.: BRASIL (1994). Tendências e Desafios da Educação Especial. Série: Atualidades Pedagógicas. Secretaria de Educação Especial. Ministério da Educação. 1994.

CHOMSKY, Noam. Reflexões sobre a linguagem. São Paulo: Cultrix, 1980.

DALCIN, Gladis. Um estranho no ninho: um estudo psicanalítico sobre a constituição da subjetividade do sujeito surdo. In.: QUADROS, Ronice Müller de. Estudos surdos I. Petrópolis: Arara Azul, 2006.

FERNADES, Eulalia. Teorias de Aquisição da Linguagem. In.: GOLDFELD, Marcia. Fundamentos em Fonoaudiologia Linguagem. Rio de Janeiro, Guanabara Koogan. 2003.

GOLDFELD, Marcia. A criança surda: linguagem e cognição numa perspectiva sociointeracionista. São Paulo, Plexus. 2002.

Surdez. In.: GOLDFELD, Marcia. Fundamentos em Fonoaudiologia Linguagem. Rio de Janeiro, Guanabara Koogan. 2003.

HUNGRIA, Hélio. Manual de Otorrinolaringologia. Rio de Janeiro, Guanabara Koogan. 2000.

LACERDA, Cristina B.; LODI, Ana Claudia. O desenvolvimento do narrar em crianças surdas: o contexto de grupo e a importância da língua de sinais. Temas desenvolvimentais, v. 15, n. 85/86, p. 45-53, 2006.

LACERDA, Cristina B. A inclusão escolar de alunos surdos: o que dizem alunos, professores e intérpretes sobre esta experiência. Cad. Cedes, v. 26, n. 69, p. 163-184, 2006. Disponível em <http://www.cedes.unicamp.br> acesso em 16 de maio de 2016.

LIMA, Marisa Dias. Um estudo sobre a aquisição de ordem e concordância no português escrito por surdos. Dissertação de Mestrado. Instituto de Letras. Universidade de Brasília, 2011.

LODI, Ana Cláudia Balieiro. A leitura como espaço discursivo de construção de sentidos: oficina com surdos. Tese de Doutorado. Pontifícia Universidade Católica de São Paulo, 2004. 
LÜDKE, M., ANDRÉ, M. E. D. A. Pesquisa em Educação: abordagens qualitativas. São Paulo: E.P.U., 1986.

LYONS, John. Linguagem e linguística: uma introdução. Rio de Janeiro: LTC, 1987.

MESERLIAN, Kátia Tavares; VITALIANO, Célia Regina. Análise sobre a trajetória histórica da educação dos surdos. Anais do IX Congresso Nacional de Educação (Educere) e III Encontro Sul Brasileiro de Psicopedagogia. Paraná, 2009.

MACHADO, Paulo César. Integração/Inclusão na escola regular: um olhar do egresso surdo. In.: QUADROS, Ronice de Müller (Org.). Estudos Surdos I. Série Pesquisas. p. 38-75. Rio de Janeiro: Arara Azul, 2006.

QUADROS, Ronice Müller de. Educação de surdos: a aquisição da linguagem. Porto Alegre: Artes Médicas, 1997.

inclusão/exclusão. Ponto de Vista, nº 05. Florianópolis. 2003.

Situando as diferenças implicadas na educação de surdos:

O tradutor e intérprete de língua brasileira de sinais e língua portuguesa. Secretaria de Educação Especial; Programa Nacional de Apoio à Educação de Surdos - Brasília: MEC; SEESP, 2004.

MEC, SEESP, 2006.

Ideias para ensinar português para alunos surdos. Brasília:

RAZUCK, Renata Cardoso de Sá Ribeiro. A Pessoa Surda e Suas Possibilidades no Processo de Aprendizagem e Escolarização. Universidade de Brasília. Brasília. 2011.

SACKS, Oliver. Vendo vozes: uma viagem ao mundo dos surdos. São Paulo, Companhia das Letras. 2010.

SALLES, Heloisa Maria Moreira Lima; NAVES, Rozana Reigota. Estudos gerativos: fundamentos teóricos de aquisição de L1 e L2. In.: SALLES, Heloisa Moreira Lima; NAVES, Rozana Reigota. Estudos gerativos de língua de sinais brasileira e de aquisição de português (L2) por surdos. Goiânia: Cânone Editorial, 2010.

SILVA, Danilo da; FERNANDES, Sueli; NASCIMENTO, Ana Carolina e Silva Goyos. O decreto 5526/2005 e as diretrizes para a inclusão social dos surdos. Secretaria Municipal de Educação de Pinhais. Anais do Seminário Internacional de Pinhais. Paraná. 2015. Disponível em:<http://www.pinhais.pr.gov.br/aprefeitura/secretariaseorgaos/educacao/seminario/FreeCompone nt353content10335.shtml > Acesso em 04 jun. 2016.

SOUZA, Silvani de. Educação de surdos: a construção da identidade e a apropriação cultural no ambiente da escola polo (inclusiva) da rede estadual de Santa Catarina. Universidade Federal de Santa Catarina. Florianópolis. 2011. Disponível em: <https://repositorio.ufsc.br/bitstream/handle/123456789/95165/293185.pdf?sequence=1> Acesso em 08 jun. 2016.

STROBEL, Karin Lilian. A visão histórica da in(ex)clusão dos surdos nas escolas. ETD: Educaçao Temática Digital, Vol. 7, $\mathrm{N}^{\mathrm{o}}$. 2, $2006 . \quad$ Disponível em: http://dialnet.unirioja.es/servlet/articulo?codigo=4856345. Acesso em 10 jul. 2016. 
TUXI, Patrícia. A atuação do intérprete educacional no ensino fundamental. Dissertação de Mestrado. Faculdade de Educação. Universidade de Brasília, 2009.

Recebido em: 01.06.2016 Aceito em: 18.05.2017 